\title{
SPRAYFORMING OPTIMISATION OF SUPERALLOY AEROENGINE COMPONENTS
}

\author{
Oscar Caballero ${ }^{1}$, Dominique Fournier ${ }^{2}$, Wilfried Smarsly ${ }^{3}$ \\ ${ }^{1}$ ITP, S.A., Edificio no.300, Parque Tecnológico, Zamudio 48170, Spain \\ 2 Turbomeca, Bordes 64511, France \\ ${ }^{3}$ MTU Aero Engines, Dachauer Straße 665, Munich 80995, Germany
}

Keywords: Sprayforming, aeroengine components, 718 alloy, 720 alloy, tensile tests

\begin{abstract}
The use of the sprayforming technologies has extended in several automotive applications, with a range of components manufactured from different alloys like tool steels, aluminium, bronze. Recent results of the European funded research project OPTISPRAY Nr. GRD1-2001-40168 are presented here on the application of this process to the manufacture of Aeroengine Components in IN718 and U720 alloys. These components are mainly Low Pressure Turbine casings (and likely others of similar geometries), where the much shorter proposed manufacturing route would mean a significant cost reduction. The process key parameters ruling final results have been investigated and optimized, with the aid of modeling, to finally obtain a product with the appropriate quality to be used in the intended aerospace application. A different previous paper focuses on the spraying process parameters and post-processing routes optimization, performing the metallurgical study of the produced material. Herein, the products coming from these different routes have been assessed through mechanical tests, and the results are presented. All considered facts of technical suitability and economy of the proposed manufacturing route indicate the interest of availability of the process for aeroengine manufacturers.
\end{abstract}

\section{Introduction}

The type of spray formed components or geometries that present a higher benefit for the aeronautic industry look like rings or hollow cylinders as the ones shown in Figure 1. The components shown in this figure are compressor cases and intermediate pressure and low pressure turbine cases. In the same figure, the typical preform of a ring as is obtained after the deposition (prior to further operations such as thermomecanical processing, machining, etc.) is shown.

The main advantage of this type of components when they are produced by spray forming is the reduction of the number of processing steps that is achieved when this technology is employed. Spray forming circumvents many of the processing steps traditionally required prior to a ring rolling operation. At the same time, the material that is punched out in conventional operations is saved, because the spray forming of ring shapes directly gives the preforms required for ring rolling, which automatically gives rise to a cost reduction. At the same time, this amount of punched out material that is usually lost in conventional ring rolling, is not lost in the spray forming of rings because all the sprayed material is directly collected in the shape of a ring. 


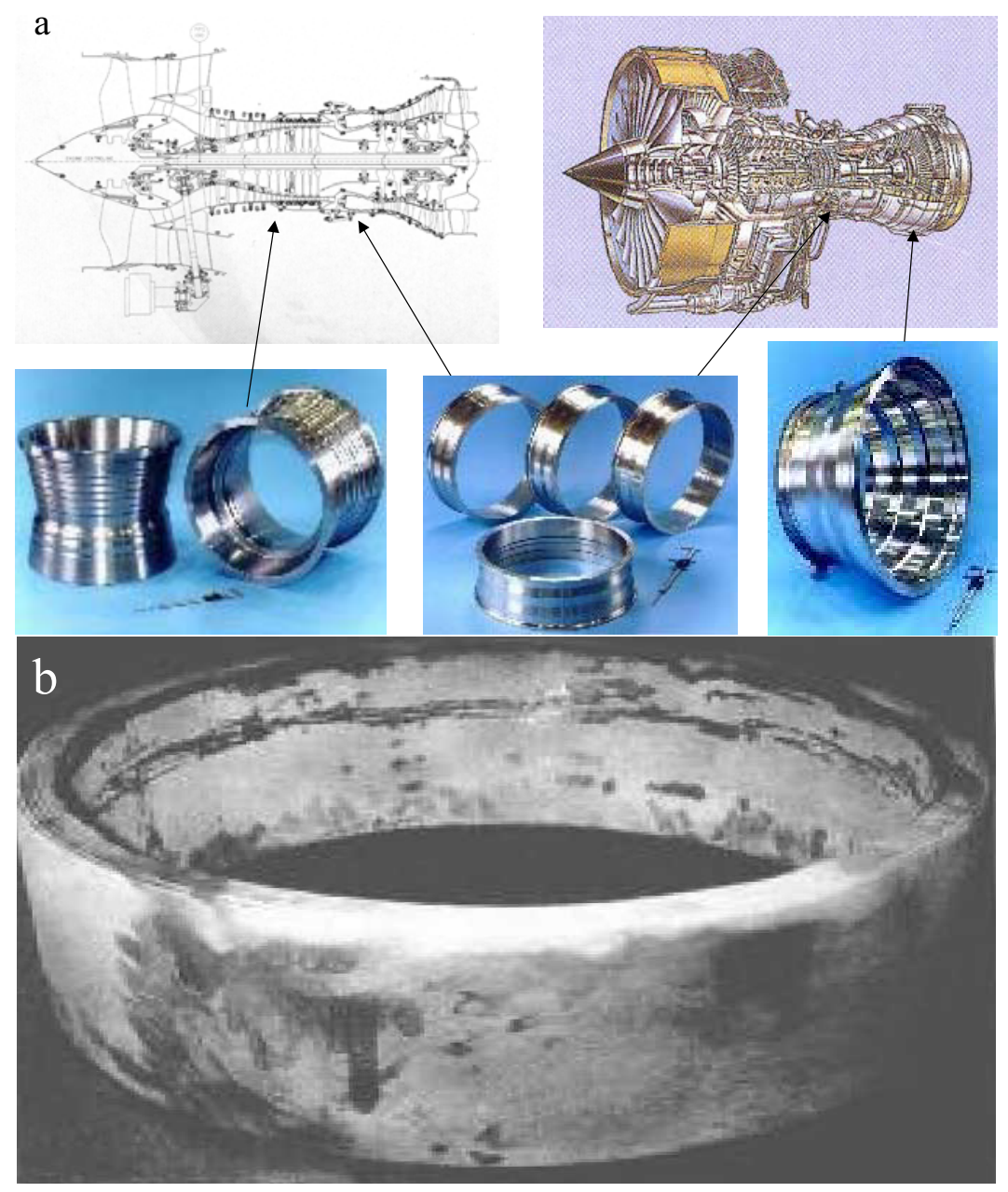

Fig. 1.a.- Examples of the components that can be manufactured with spray forming. b.- Ring preform Ref [7].

Apart from the reduction of processing steps and the reduction of the amount of raw material, it has to be noticed that the raw material sources employed in the spray forming and in the conventional ring rolling are absolutely different. Conventional ring rolling requires a high quality raw material source, usually a billet from a double melted material. The billets are obtained after several forging operations carried out on an ingot. These forging operations are required to turn the solidification microstructure into a fine grained microstructure with a better balance of mechanical properties. The billets thus manufactured have to be adequately inspected to ensure its quality, which gives rise to an additional cost of the final product.

So the spray forming of rings causes a clear cost reduction in several ways: reduction of processing steps, reduction of the net weight of material required and reduction of the quality of the raw material employed.

According to the type of component that has to be manufactured, and in line with its mechanical requirements, sometimes the material obtained directly after the deposition is good enough but sometimes it requires post processing operations. With this post processing the grain structure is further refined giving rise to an enhancement of the mechanical behaviour of the material. In any case, as explained, even when some post processing operations are required, spray forming can be more cost effective and more interesting than conventional ring rolling. 


\section{Post-processing of material}

The optimised rings produced in the facility at the University of Bremen for the Optispray project in the IN718 and U720 alloys were processed by Böhler Edelsthal and Böhler Schmiedetechnik at Kapfenberg by three different routes. These were the sprayed and HIPed material one, the sprayed and forged one, and a third one including both previous postprocessing operations, HIP and forging afterwards. These were selected as the information on the as-sprayed materials showed that a certain amount of porosity was still remaining on the rings after the spraying process. This was higher at the inner and outer surface areas of the rings, zones corresponding to the non-steady state regions of the process, for the stabilisation during first minutes and also for the last deposited layers.

The optimisation of the spraying process achieved a significant reduction of this porosity compared to that reported in previous works, specially in the area just above the substrate, as shown in the following Figure 2:

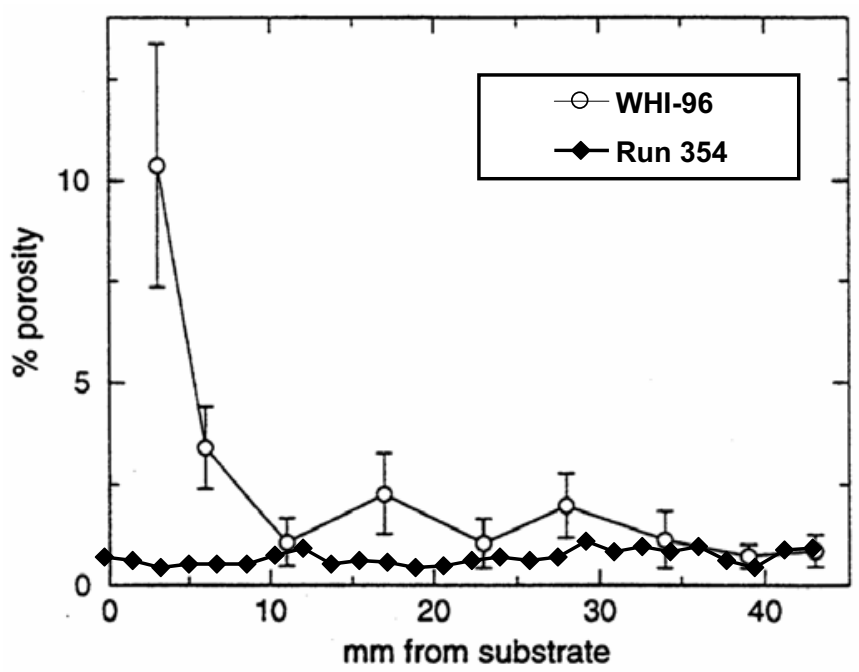

Fig. 2.- As-sprayed porosity versus thickness of an In718 ring using argon for atomisation [8],

Comparison of run 354 and data from literature (ED Whitton, PS Grant, D Bryant:

Microstructural evolution in spray formed IN718 Nickel superalloys. Proc. ICSF III, 1996, Cardiff, UK, p. 89-99).

However, to keep the aerospace standards (zero porosity at currently used forgings) and thus allow placing this kind of material into the final components, porosity must be completely suppressed. Consequently, some degree of post-processing is needed. The HIP process is usually employed with castings to heal this porosity, inherent to that manufacturing process, so the first option was to apply it to the produced rings. It on the other hand means that no change of shape from the original ring is achieved, so the final component must be contained in it. Just the machining operations are done afterwards to obtain the final geometry.

Secondly, the contrary case was also considered, and material was treated as an intermediate forged product. This meant that the forging steps missing to the final geometry are considered. The effect on the hot working on the material is double. On the one hand, it can help to close the remaining porosity, as compressive stresses are being applied. On the other, the hot working of the material would of course cause a finer microstructure on it, and better mechanical properties would be achieved. Nevertheless, tensile regions which are always present during thermomechanical treatment may show fracture because of the not closed pores, so the application of only this post-processing method might be not fully satisfactory, either. 
Finally, a third route was tested were the two previous processes were combined. Reasoning behind is that the application of HIP in first place would help in healing remaining porosity, thus allowing for a more robust forging process, as this remaining porosity proved to act as crack initiation sites when any tensile stresses appear on them while the material flows in the forging process.

Figure 3 summarises the assessed routes and shows photographs of the obtained rings and forged bits of In718 and Udimet 720 alloys. More details on these operations are presented on a different paper at this conference [9].

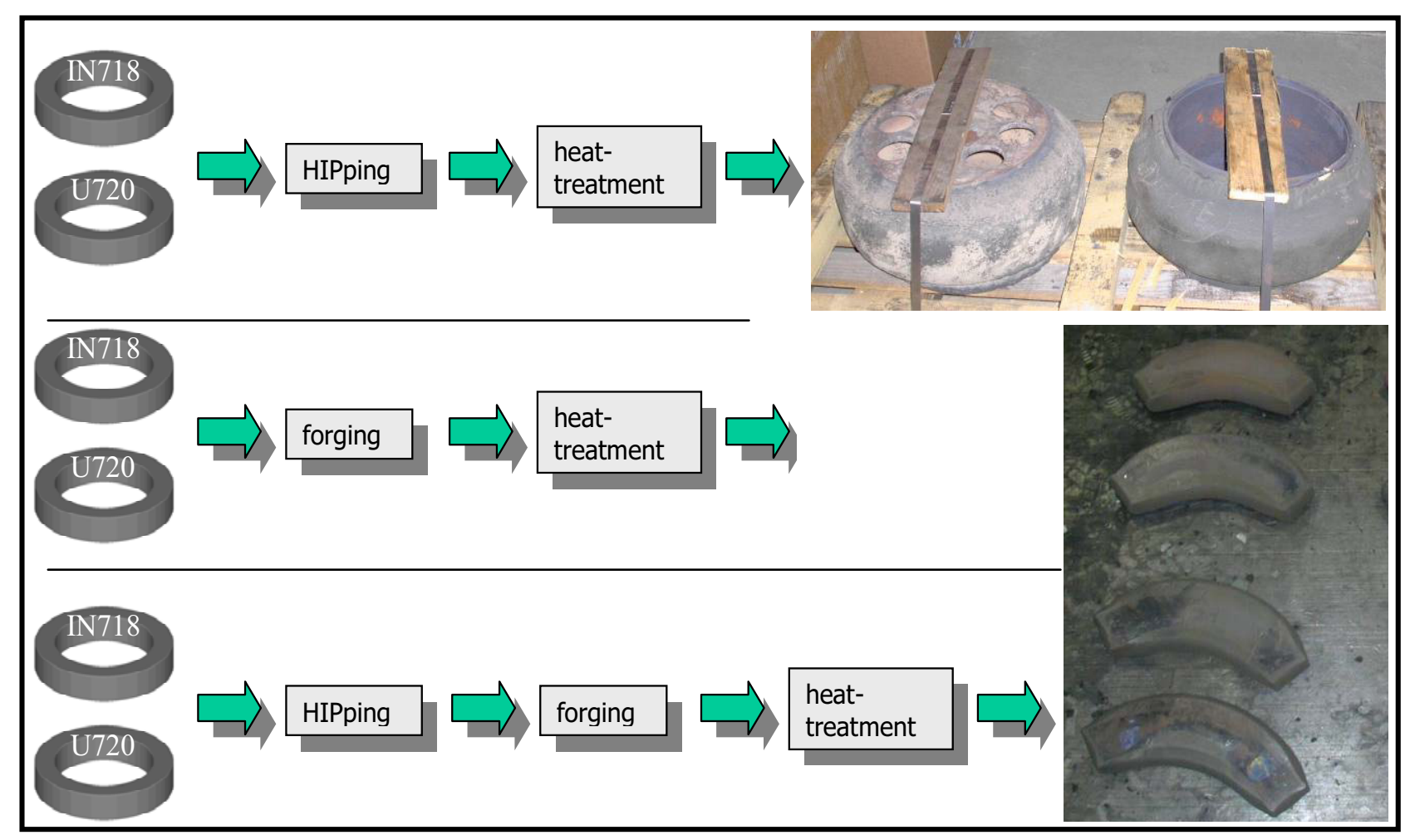

Fig. 3.- Different post-processing routes.

\section{Experimental procedure}

Six rings were used for the mechanical testing, one of each alloy for each manufacturing route. Regarding the hot worked material, not every area from the same piece shows the same microstructure, but different textures can be found due to the different levels of hot working placed on the material. Figure 4.a shows how the structure of the material changes depending on the amount of hot working that is has undergone. This was considered when excising mechanical test samples. Having this in mind, the samples were cut from the centre of the forged bits (as shown in Figure 4.b), where the higher amount of deformation and also better closure of pores is achieved. Mechanical test samples were taken from the forged bits mostly in the circunferential direction, as shown in Figure 5. 


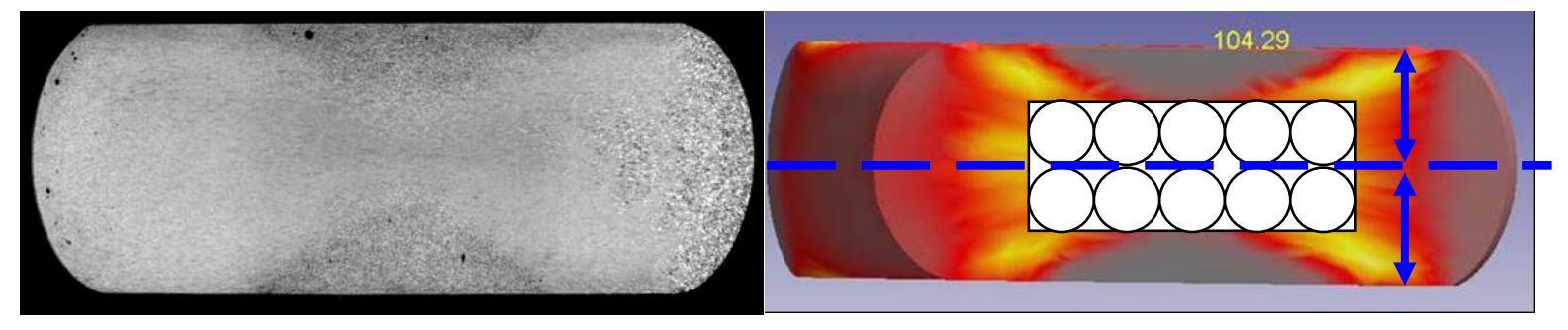

Fig. 4.a.- Effect of hot working on material texture, depending on microstructure. b.- Sketch for sample excising on forged bit cut.

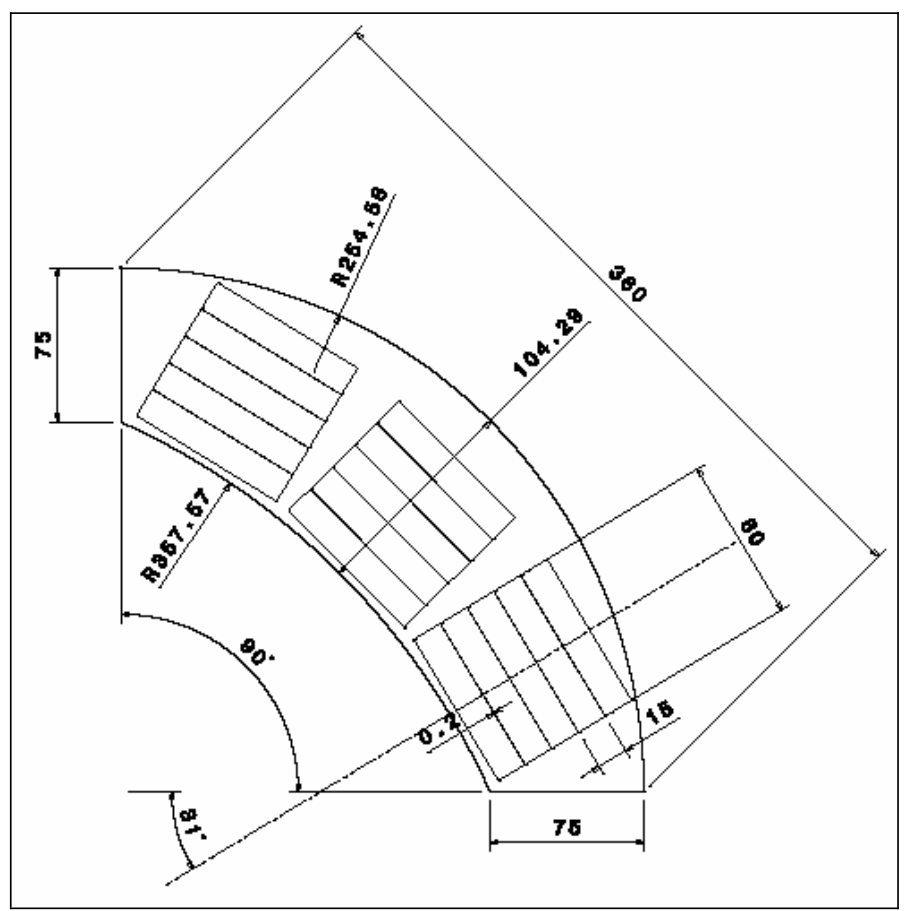

Fig. 5.- Sketch for sample excising.

\section{Mechanical test results}

\section{$\underline{\text { IN } 718}$}

The values obtained at tensile tests show that mechanical properties of the obtained parts met the required values of the equivalent forged material. Margins of over 20\% excess have been obtained. Basis for comparison is the AMS 5662 specification, commonly accepted by all aeroengine manufacturers. Details on values obtained for each different manufacturing route, and comparison with previous values published from different sources follow.

\section{$\underline{\text { HIPed material }}$}

The material that only underwent HIP shows acceptable results for both UTS and PS. In fact the PS values are quite meeting the original UTS requirement. A significant margin exists over the required minimums to consider the material pretty interesting to use. Values are also comparable to those reported by ref. [5], though lower in some extent. Figure 6 shows comparison with ref. [5] and AMS specification. 


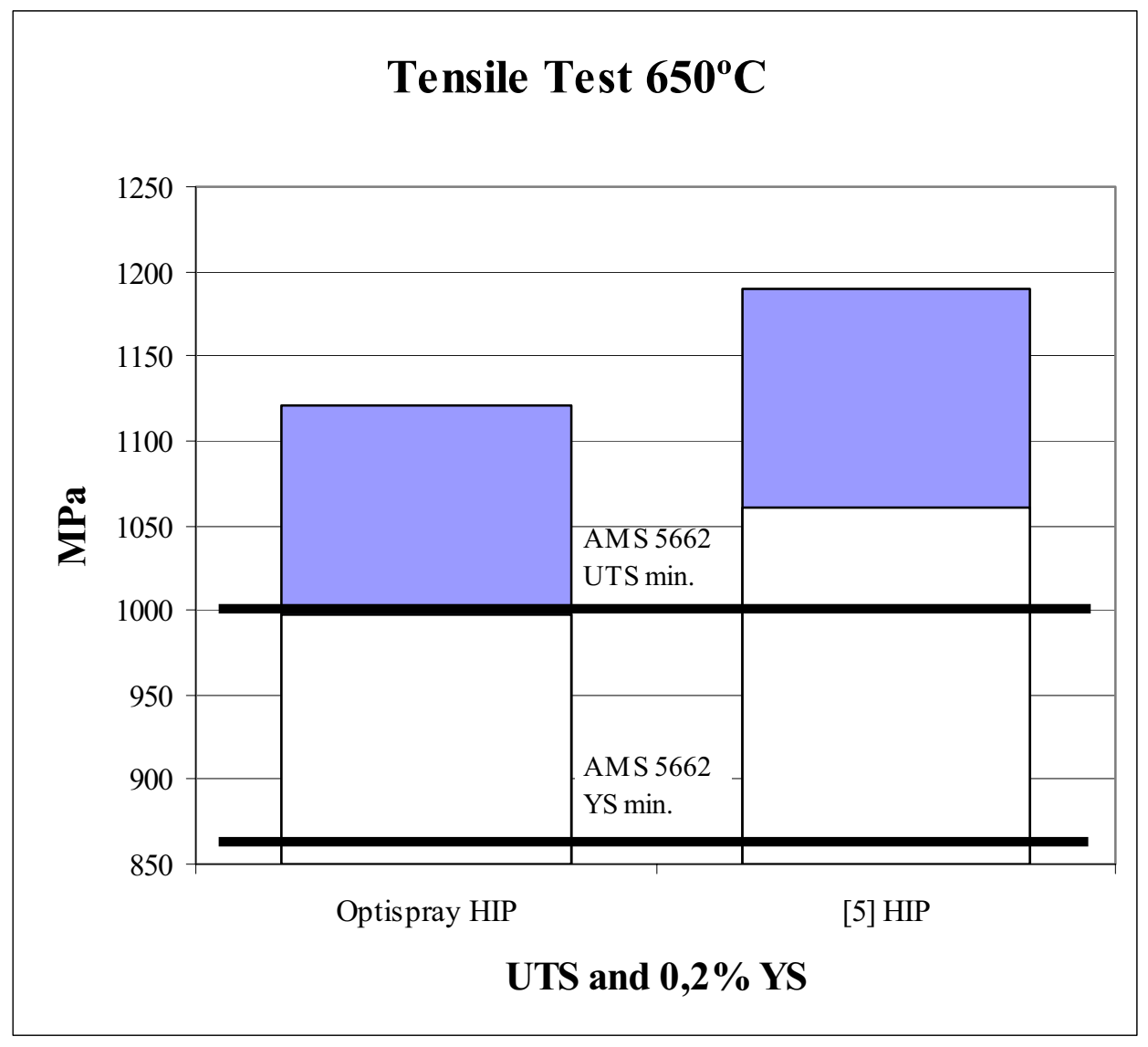

Fig.6.- UTS and YS values from $650^{\circ} \mathrm{C}$ tensile tests on IN 718 HIPed material

Ductility values also meet the specification minimum requirement. In this case, ductility values shows a better result than that obtained in ref. [5]. In both cases the obtained results are well above the required $12 \%$, but Optispray material ductility raises to about $17 \%$, while in ref [5], a value of approximately $15 \%$ is reported.

These high values are particularly interesting, as containment requirements place a high demand on this property. As previously mentioned, the process particular features make it interesting specially for casings. These are designed under the requirement of being able to contain blades in case of being released for any circumstance from the engine disks. The high rotating speed of these component results in a high kinetic energy, which has to be withstood by the casing. This is a function of the UTS, and also of the ductility of the material for the casing. Consequently, both values should be high enough to meet this containment requirement.

\section{$\underline{\text { Hot Worked material }}$}

For hot worked material, AMS requirements are again met with high margins. Figures 7 and 8 show a comparison with other values reported from Refs [2], [5], and [6] at $650^{\circ} \mathrm{C}$, and from Refs [1], [2], [3], and [6] at RT, respectively. Regardless the different routes or the amount of hot working or deformation imposed to the material in the considered references, all reported values are pretty consistent, with low scatter for UTS values. This scatter increases for YS values, but in any case it is always well above the requirements. 


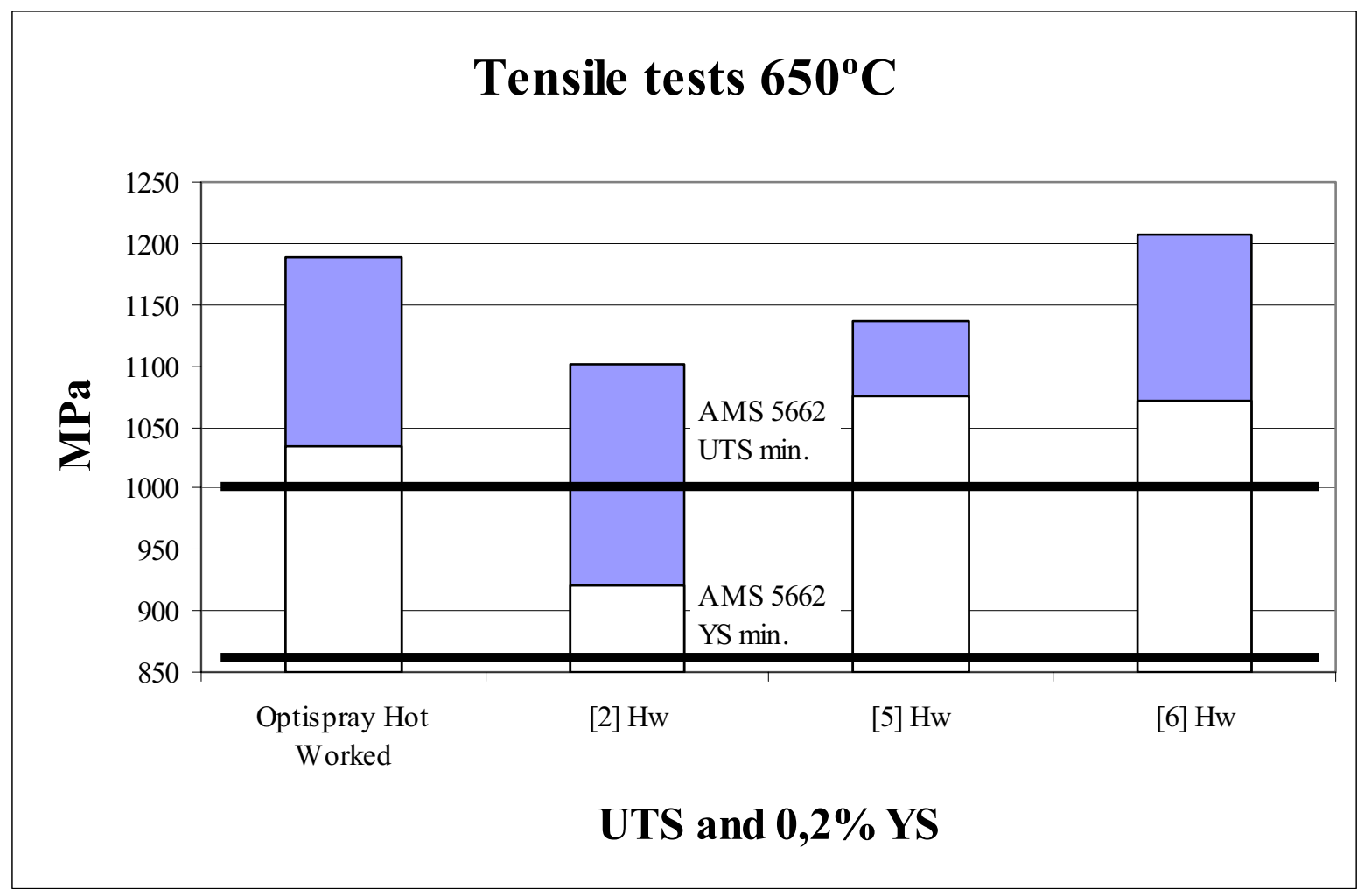

Fig. 7.- UTS and YS values from $650^{\circ} \mathrm{C}$ tensile tests on IN 718 hot worked material

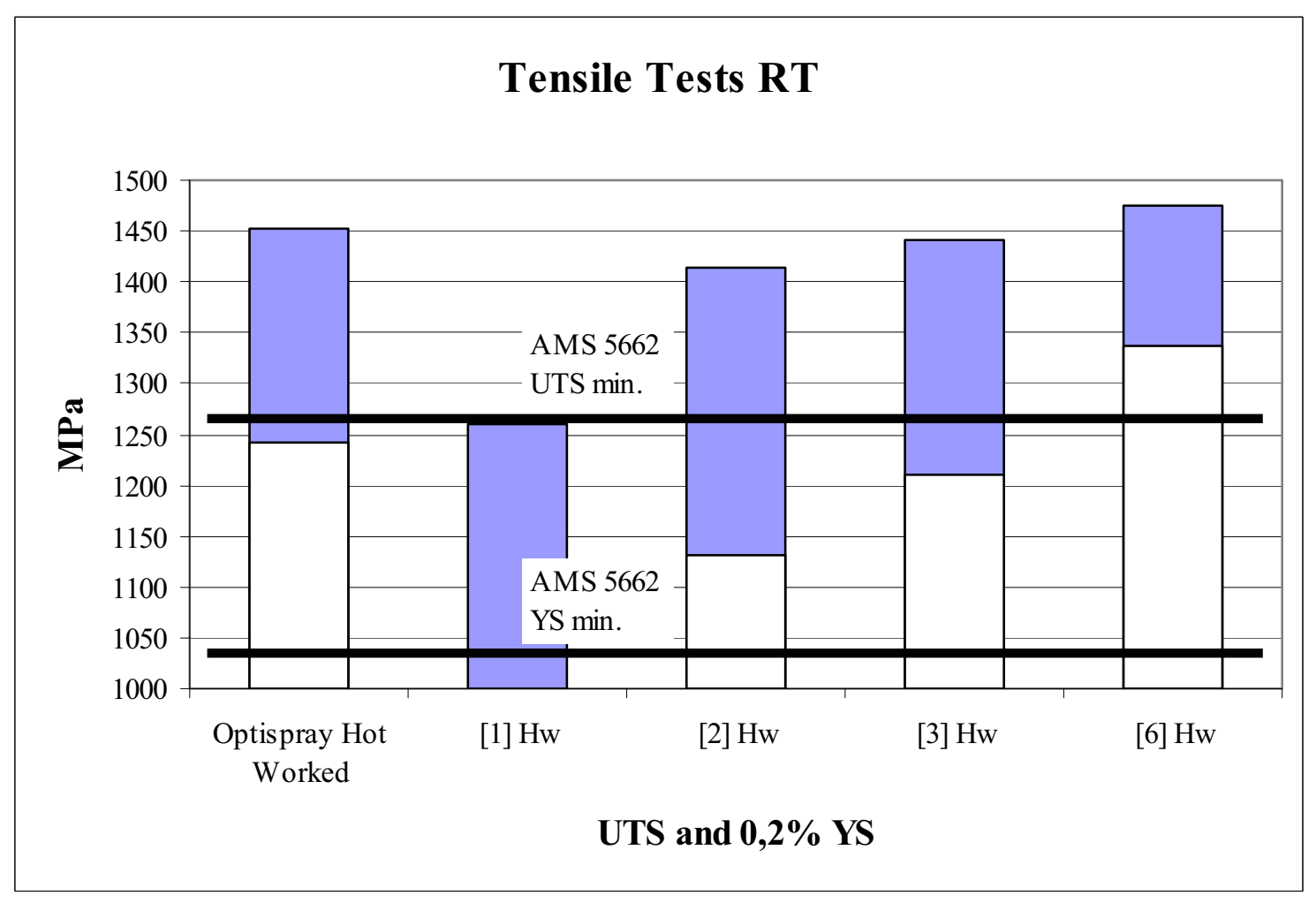

Fig. 8.- UTS and YS values from RT tensile tests on IN 718 hot worked material 
Large scatter is noticed however in ductility, both at $650^{\circ} \mathrm{C}$ and RT, as seen in Figures 9 and 10 , specially with ref. [2]. This could be related to the forging process used in this case, more specific to disk material, and also to the use of ESR, leading to a cleaner material. AMS requirements are met again.

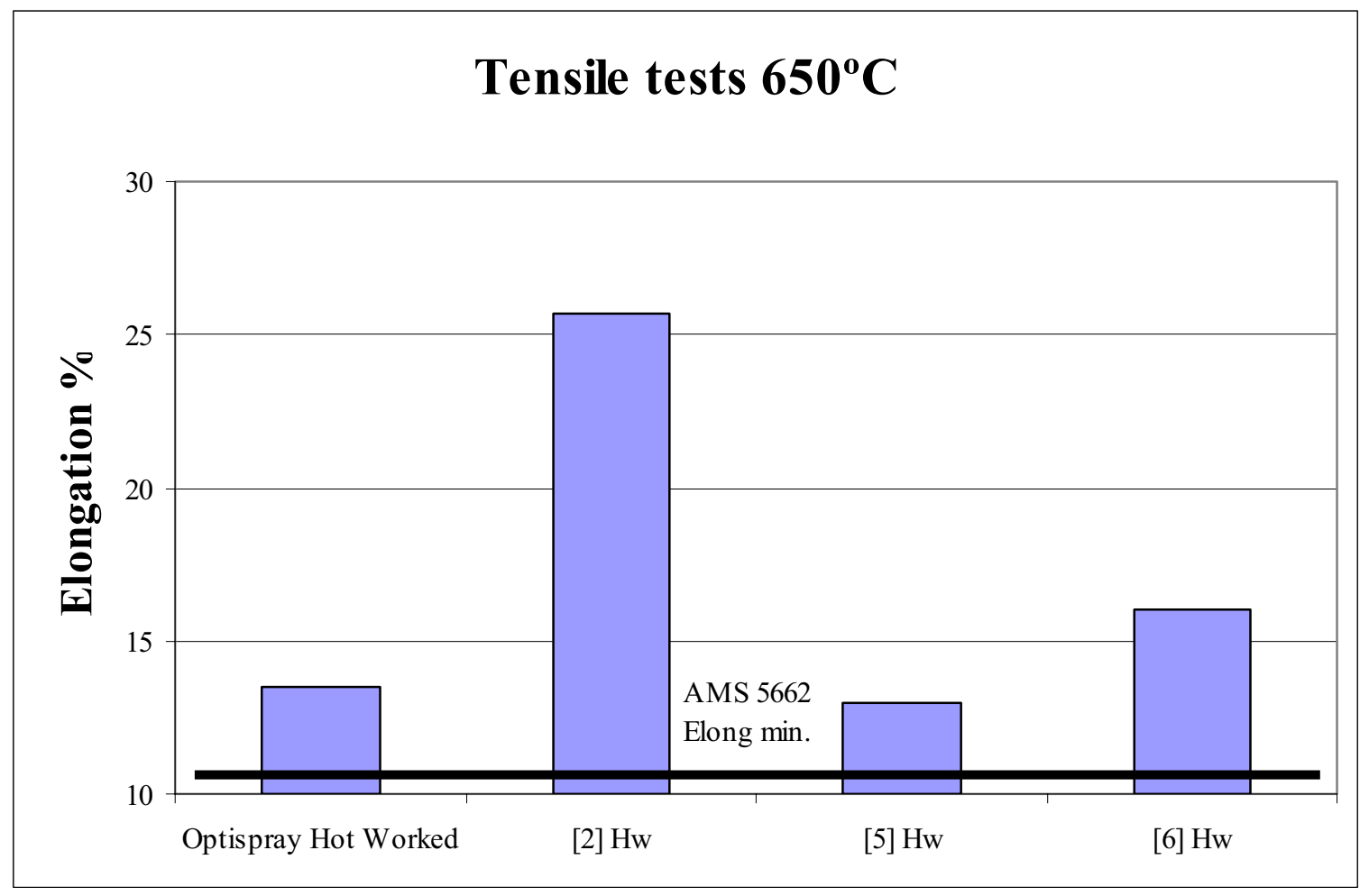

Fig. 9.- Ductility values from $650^{\circ} \mathrm{C}$ tensile tests on IN 718 hot worked material

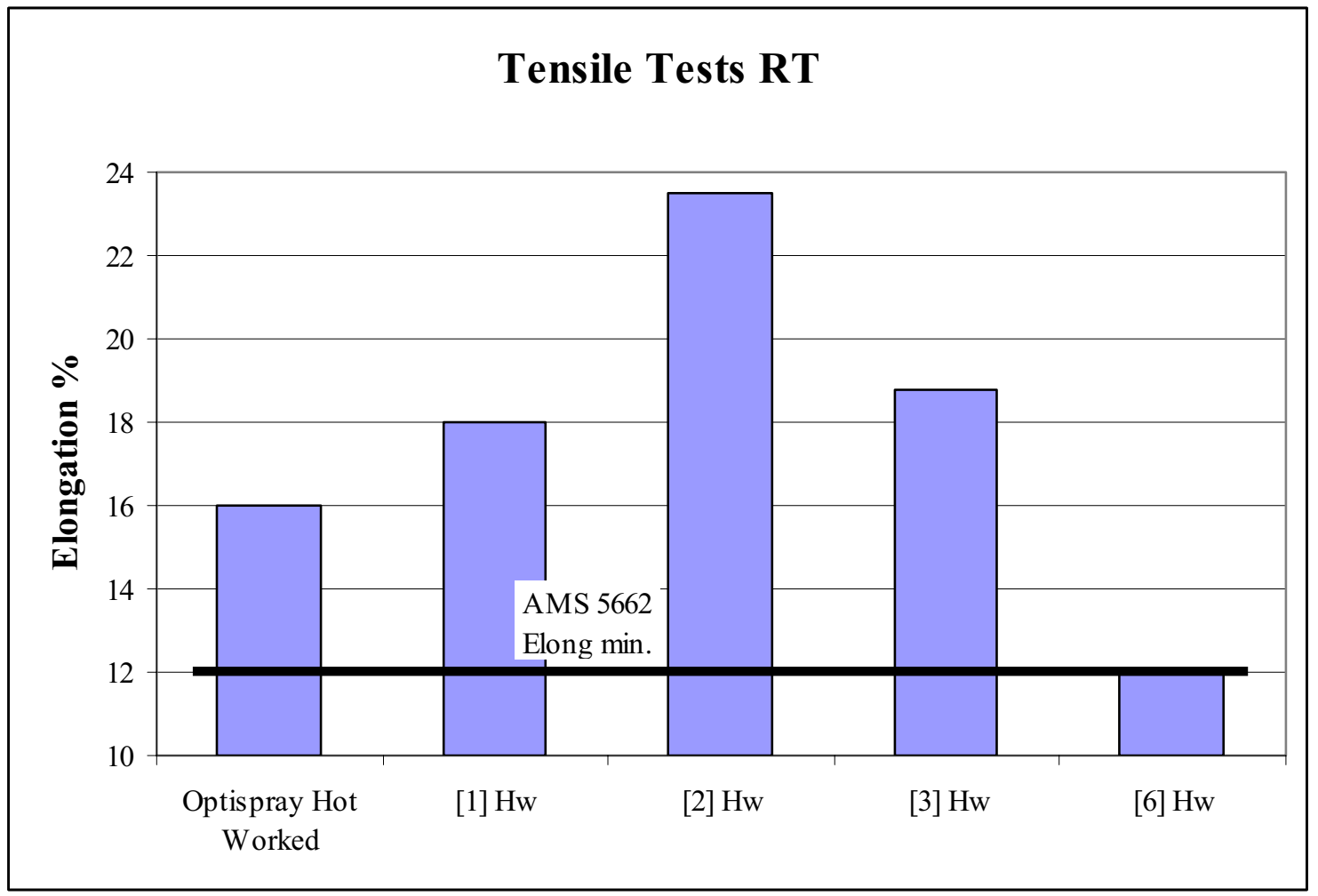

Fig. 10.- Ductility values from RT tensile tests on IN 718 hot worked material 


\section{$\underline{\text { HIPed and hot worked material }}$}

The most complex route obtains the best results on mechanical properties. Results are better than those reported in Ref [4], on material also incorporating both post-processing operations, as shown in Figures 11 and 12 for $650^{\circ} \mathrm{C}$ and RT Tensile tests.

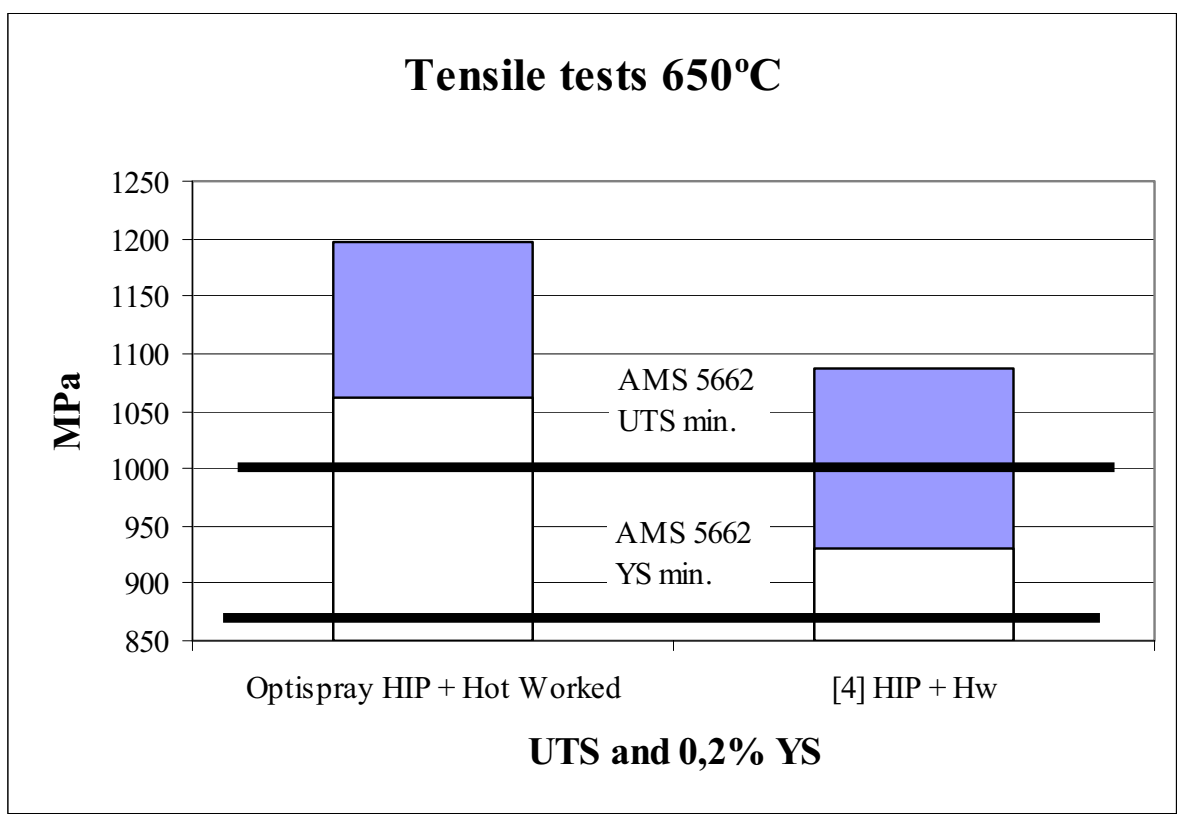

Fig. 11.- UTS and YS values from $650^{\circ} \mathrm{C}$ tensile tests on IN $718 \mathrm{HIP}$ and hot worked material

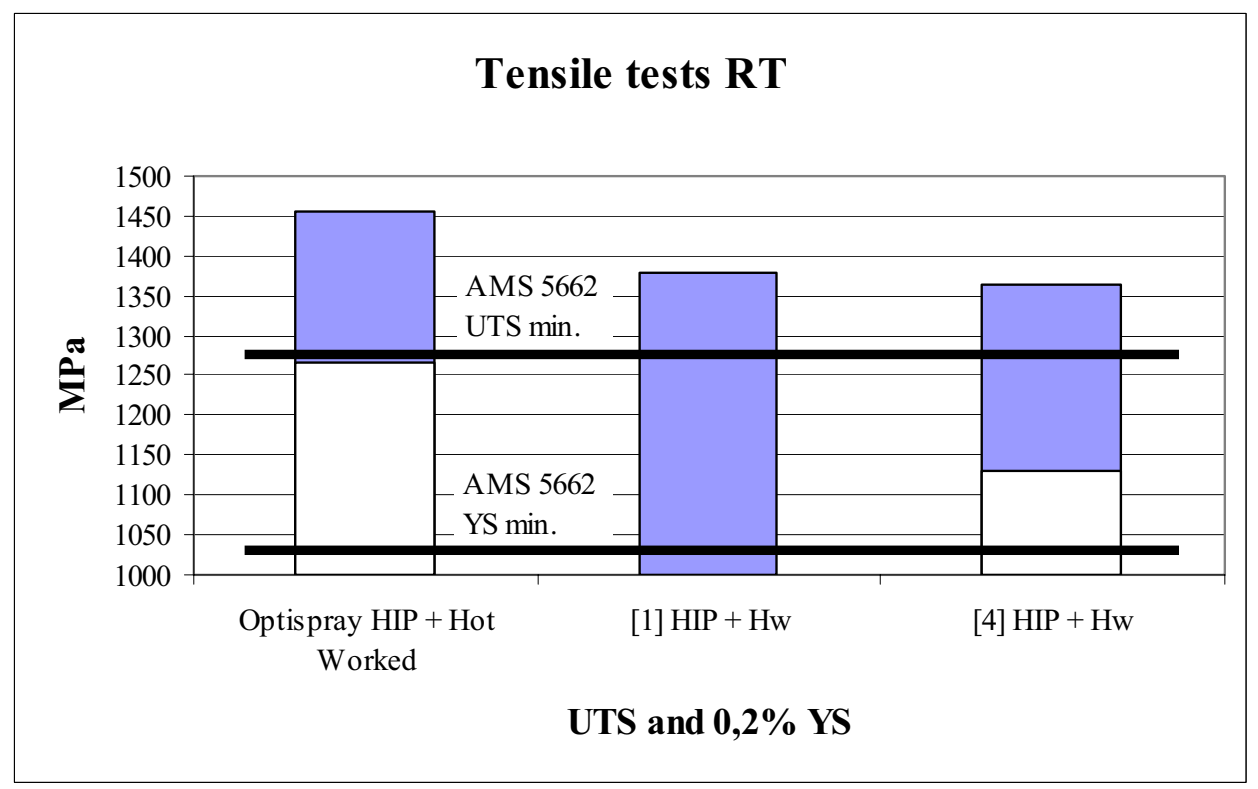

Fig. 12.- UTS and YS values from RT tensile tests on IN 718 HIP and hot worked material

Ductility values from these tests for the Optispray material are well above the minimum requirements. Values of 15 and $17 \%$ were obtained at $650^{\circ} \mathrm{C}$ and RT tests, where the AMS minimums are $12 \%$ at both temperatures. 
IN 718 UTS and YS comparison of HIP and hot worked, only hot worked, and only HIPed, is shown in Figure 13. It can be observed in the graph that the mechanical test results are very similar for the three post-processing routes. Only marginal benefits can be obtained regarding UTS and YS from the application of HIP before performing the forging operations. This fits with the previous observation of no differences observed in the microstructure of both routes. Thus, from an economical point of view, it shouldn't be worth to apply HIP to the material which is going to be subsequently forged, at least when considering expected improvements on UTS and YS. Application of only HIP shows the lowest values of the three routes, as observed with tests at $650^{\circ} \mathrm{C}$.

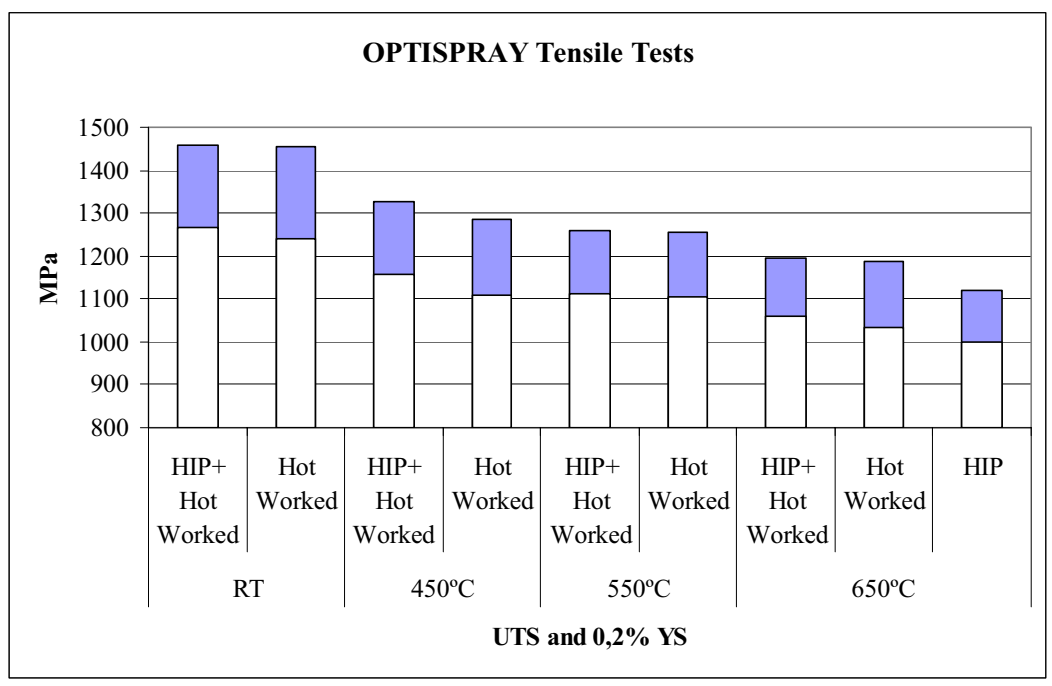

Fig. 13.- UTS and YS values from tensile tests at different temperatures on IN 718 material processed by different routes.

However, some differences can be observed regarding ductility. Here, application of HIP is showing always an improvement in obtained values. This is thought to be due to the likely effect of the minor amount of remaining porosity in reducing this value for the not-HIPed material.

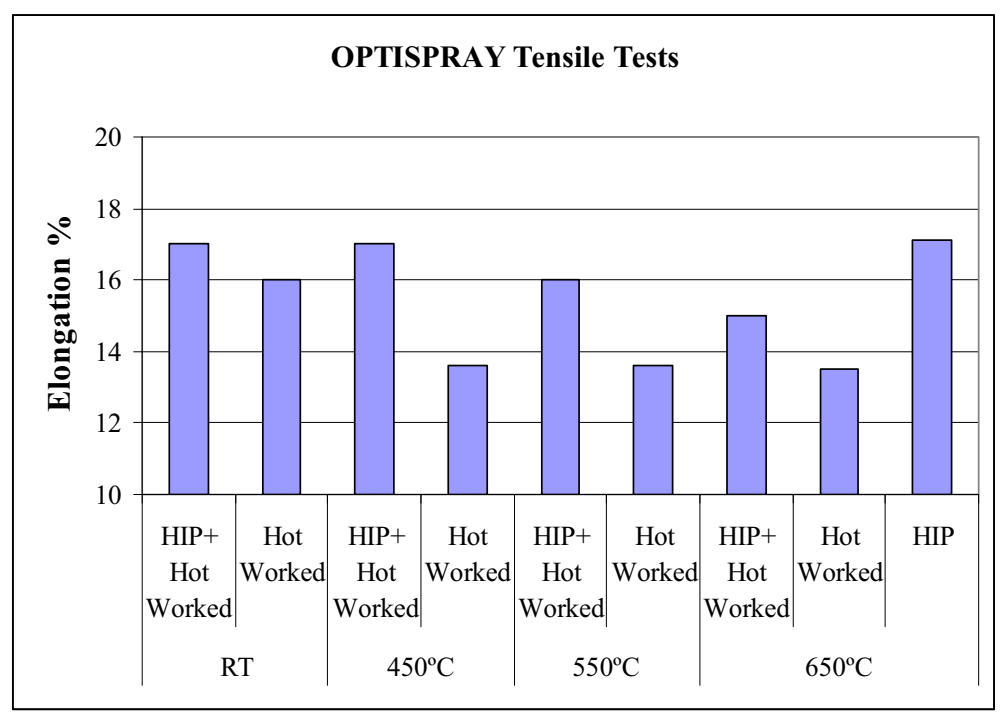

Fig. 14.- Ductility values from tensile tests at different temperatures on IN 718 material processed by different routes. 
For Udimet 720 alloy, tensile tests have again revealed that the material properties meet the usual requirements from aeroengine manufacturers, though this time the wide margin that was available in the case of the Inconel 718 alloy is no longer present. Figures 15 and 16 show the values obtained for this alloy.

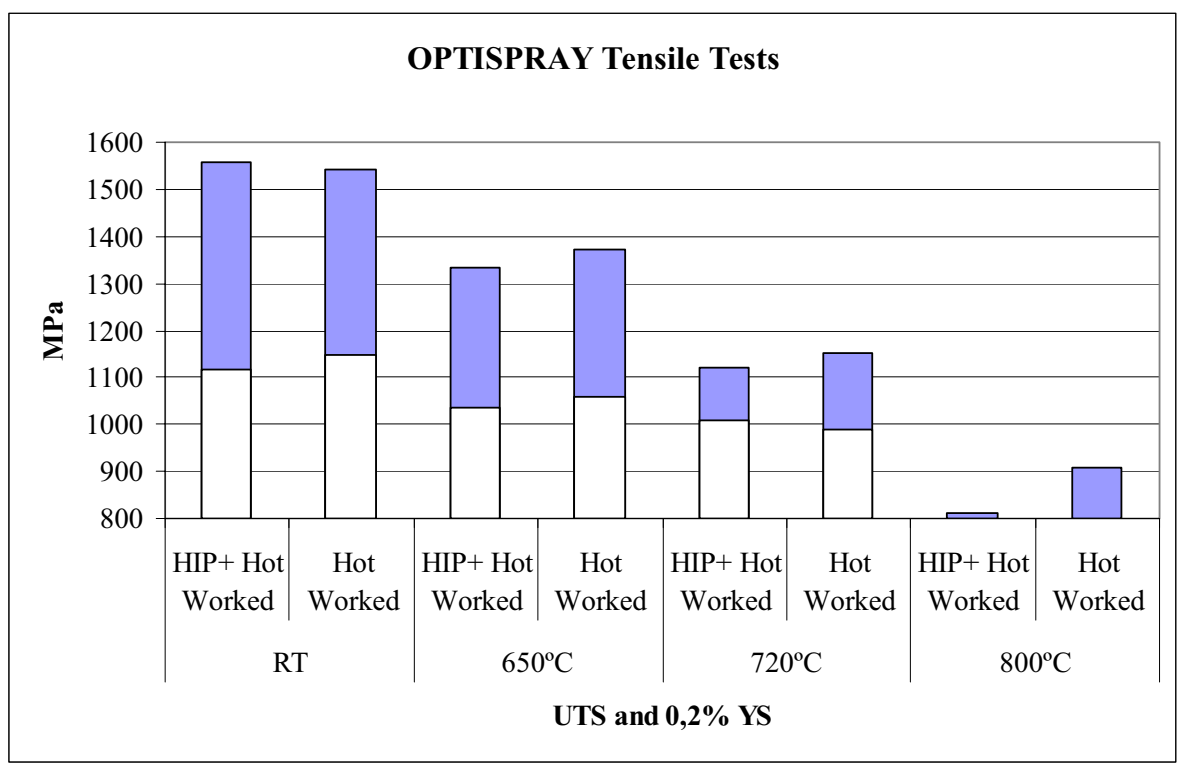

Fig. 15.- UTS and YS values from tensile tests at different temperatures on U720 material processed by different routes.

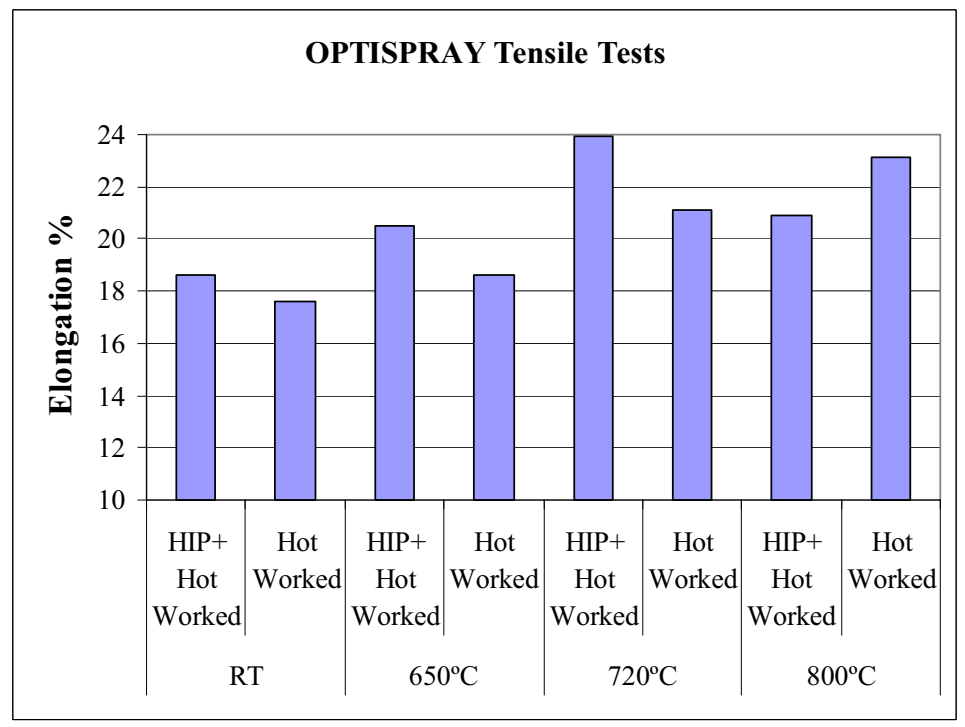

Fig. 16.- Ductility values from tensile tests at different temperatures on U720 material processed by different routes.

In this material, the application of the HIP process is not showing any noticeable improvement on the obtained mechanical test results. Again, very similar values are obtained with or without applying the HIP, except in the case of higher temperature, where a debit can be noticed when HIP has been applied. It clearly makes no sense in this case to follow this more complex route. 


\section{Conclusions}

- Sprayformed material post-processed by different routes meets the usual specification requirements placed on forged material, showing in many cases wide margins over those requirements.

- The residual porosity that remains on the as-sprayed material is healed by the post-processing operations, such as HIP and forging. No detrimental effect from that previous porosity could be observed on the tensile properties of the materials.

- When the as-sprayed material is forged, this process is quite enough to get rid of the remaining porosity. Application of HIP before forging shows little improvement on mechanical properties (mainly in ductility), though it may be required for manufacturing issues.

- Given that the mechanical properties requirements of parts produced by the sprayforming method are met, this supports the interest of using the process as a cost reduction opportunity, replacing the more complex routes of forgings.

\section{Future Work and Final component}

Other kind of tests, like LCF, Charpy, creep and stress rupture, will be performed on the produced material. All these will allow completing the study of the produced material and giving further comparisons of the three different post-processing routes.

Besides, two different component prototypes have been produced, following the routes of only HIP (simplest) and the complete HIP + ring rolling one (most complex). These will be assessed in more detail, including more mechanical tests and other manufacturing operations, such as machining, to further assess feasibility of producing components from this kind of material.

For the simplest one, the alloy 720 was chosen, and a part was due to be produced by Turbomeca. For the most complex route, IN 718 alloy was chosen. Here a component was produced also from the sprayed rings, but now including the different operations or manufacturing steps that were considered in the study (as HIP) or that were necessary to achieve the final geometry (ring rolling).

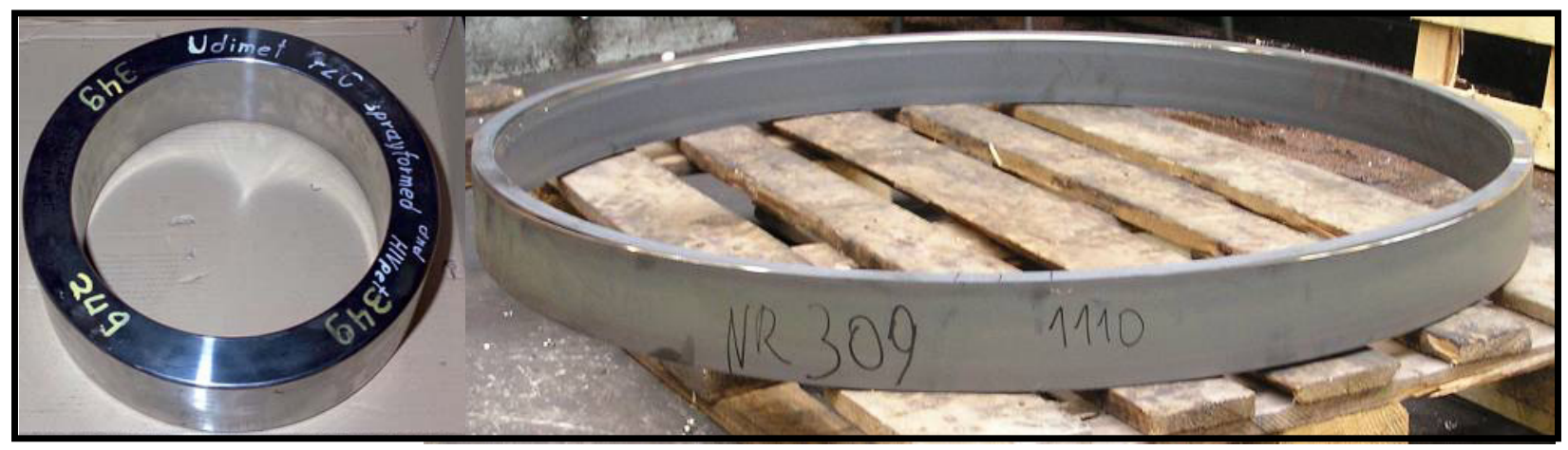

Fig. 17.- Component prototypes produced using the simplest (on Udimet 720) and most complex (on IN 718) post processing routes. 


\section{Acknowledgements}

The authors are grateful to Garbiñe Atxaga (from INASMET research centre, also a partner in the OPTISPRAY project), for her contribution in performing part of the mechanical tests of the alloys, and to the authors of Refs [8] and [9] (from University of Bremen, Böhler Edelstahl and Böhler Schmiedetechnik, also participating in the project), for their inputs to this paper. Also to the European Union which supported the work under the Sixth Framework Research and Development Growth program with the project number G4RD-CT 2002-00762.

\section{References}

[1] M.D. Barratt, A.L. Dowson, M.H. Jacobs, "The Microstructure and Properties of IN718 Rings Produced by Centrifugal Spray Deposition", Proceedings of the Fifth International Conference on Spray Forming, Bremen, Germany, 2003, Part 5, 57-68

[2] W.T. Carter, Jr, M.G. Benz, J. K. Browning, R.J. Zabala, B.A. Knudsen, R.M. Forbes Jones, R.M. Davis, "Clean Metal Spray Forming" Proceedings of Superalloys 718, 625, 706 and Various Derivatives, E.A. Loria, TMS, 1997, pp. 27-36

[3] R.L. Kennedy, R.M. Davies, F.P. Vaccaro, “An Evaluation of Spray Formed Alloy 718” Proceedings of Superalloy 718 - Metallurgy and applications, E.A. Loria, The Minerals, Metals \& Materials Society, 1989, pp.97-108

[4] N. Paton, T. Cabral, K. Bowen, T. Tom, "Spraycast-X ${ }^{\circledR}$ IN718 Processing Benefits" Proceedings of Superalloys 718, 625, 706 and Various Derivatives, E.A. Loria, TMS, 1997, pp. $1-17$

[5] H.C. Fiedler, T.F. Sawyer, R.W. Kopp, A.G. Leatham, "The Spray Forming of Superalloys", Journal of Metals, Vol.39, No. 8, August, 1987, pp. 28-33

[6] M.G. Benz, R.J. Zabala, P.L. Dupree, B.A. Knudsen, W.T.Carter, T.F. Sawyer, "SprayFormed Alloy 718" Proceedings of Superalloy 718 - Metallurgy and applications, E.A. Loria, The Minerals, Metals \& Materials Society, 1987, pp.99-107

[7] P.D. Richard, R.P. Dalal, "Spraycast-X ${ }^{\circledR}$ Superalloy for Aerospace Applications" Proceedings of Superalloys 1992 , S.D. Antolovich, R.W. Stusrud, R.A. MacKay, D.L. Anton, T. Khan, R.D. Kissinger, D.L. Klarstorm, The Minerals, Metals \& Materials Society, 1992, pp.205214

[8] V. Uhlenwinkel, N. Ellendt, M. Walter, J. Tockner, "Spray forming and post.processing of superalloy rings" Proceeding of Continuous Casting of Non-ferrous Metals, 14-16 Nov. 2005, Neu-Ulm, Germany

[9] M. Walter, M. Stockinger, J. Tockner, N. Ellendt, V. Uhlenwinkel, "Spray forming and postprocessing of superalloy rings" Proceedings of Superalloys 718, 625, 706 and Various Derivatives, E.A. Loria, TMS, 2005, pp. xxxx 